Para citar este artículo: Sixto-Costoya, A., Lucas-Domínguez, R., \& Agulló-Calatayud, V. (2021). COVID-19 y su repercusión en las adicciones. Health and Addictions / Salud y Drogas, 21(1), 259-278. doi: 10.21134/haaj.v21i1.582

\title{
COVID-19 Y SU REPERCUSIÓN EN LAS ADICCIONES
}

\author{
COVID-19 AND ITS REPERCUSSION ON ADDICTIONS
}

Andrea Sixto-Costoya, Rut Lucas-Domínguez y Víctor Agulló-Calatayud

\begin{abstract}
Objetivo. Indagar acerca de la literatura científica emergente a nivel internacional sobre la repercusión de la pandemia por COVID-19 en las adicciones. Metodología. La base de datos Web of Science se utilizó para analizar la literatura científica sobre la pandemia por COVID-19 y la influencia que ésta pueda tener en el ámbito de las adicciones. Resultados. Se identificaron 320 documentos, de los cuales 38 cumplieron los criterios de inclusión. Sobresalieron tres problemáticas: el consumo de tabaco, opioides y alcohol. Según la literatura incipiente, entre los consumidores de opiáceos existe el riesgo de aumento de las sobredosis, así como un empeoramiento del binomio estrés-alcohol y un peor pronóstico de la enfermedad COVID-19 para los fumadores de tabaco. Destaca la preocupación por la disminución de servicios sanitarios focalizados en las adicciones y la salud mental. Conclusiones. La literatura es muy reciente y es necesaria más evidencia científica que arroje luz. Se pone de manifiesto la preocupación por el alcohol, opioides y tabaco, pero se constata la escasez de referencias a adicciones sin sustancia (nuevas tecnologías, juego online) o a los hipnóticos y las benzodiacepinas.
\end{abstract}

Palabras clave: adicciones, COVID-19, salud mental.

Objective. Inquire about the emerging scientific literature at the international level about the repercussion of the COVID-19 pandemic on addictions. Methodology. The Web of Science database was used to analyze the scientific literature on the COVID-19 pandemic and its influence in the field of addictions. Results. 320 documents were identified, of which 38 met the inclusion criteria. Three problems stood out: the consumption of tobacco, opioids and alcohol. According to the incipient literature, among opioid users there is a risk of increased overdoses, as well as a worsening of the stress-alcohol binomial and a worse prognosis of COVID-19 disease for tobacco smokers, the latter with some controversy. The concern about the decrease in health services focused on addictions and mental health stands out. Conclusions. The literature is very emergent and more scientific evidence is needed to shed light. The concern about alcohol, opioids and tobacco is evident, but the absence of studies on addictions without substance (new technologies, online gambling) or hypnotics and benzodiazepines is confirmed.

Keywords: addictions, COVID-19, mental health.

La COVID-19 está teniendo una enorme repercusión en la salud, así como graves consecuencias económicas y sociales (Lazcano \& Alpuche, 2020). Dentro de este contexto, existe la preocupación de que el campo de las adicciones, que ya de por sí representa un grave problema de salud pública, se vea especialmente afectado, tanto en el aspecto biomédico como psicosocial.

En el aspecto biomédico, el daño que las adicciones pueden producir, ampliamente documentado en la literatura científica, corre el riesgo de colisionar con las consecuencias que la COVID-19 puede ocasionar en el organismo, especialmente determinados factores de riesgo como la edad, la diabetes, la hipertensión, los trastornos respiratorios y el cáncer empeoran el

Andrea Sixto-Costoya, Unidad de Investigación Social y Sanitaria UISYS (CSIC-Universitat de València) y Departamento de Historia de la Ciencia y Documentación. Facultad de Medicina, Universitat de València, España, http://orcid.org/0000-0001-9162-8992. Rut Lucas-Domínguez, Unidad de Investigación Social y Sanitaria UISYS (CSIC-Universitat de València), Departamento de Historia de la Ciencia y Documentación. Facultad de Medicina, Universitat de València, España y CIBERONC, España, http://orcid.org/00000002-4697-7832.

Víctor Agulló-Calatayud, Unidad de Investigación Social y Sanitaria UISYS (CSIC-Universitat de València) y Departamento de Sociología y Antropología Social. Facultad de Ciencias Sociales, Universitat de València, España, http://orcid.org/0000-0002-07201572, correspondencia a victor.agullo@uv.es. 
pronóstico de esta enfermedad (National Institute on Drug Abuse [NIDA], 2020). En el aspecto psicosocial, el fenómeno de las adicciones podría verse agravado debido a las medidas diseñadas para hacer frente a la pandemia causada por la COVID-19. En este sentido, la mayor parte de los gobiernos han decidido llevar a cabo opciones drásticas que incluyen confinamiento, distanciamiento social, vigilancia policial, recorte de libertades públicas, reducción y restricciones de la movilidad y cierre temporal de fronteras e instituciones educativas, así como de todas las actividades productivas excepto aquellas que suministran los servicios básicos. El cumplimiento de esta normativa está provocando cambios profundos en el día a día de la población que, como están señalando científicos y epidemiólogos, podrían tener consecuencias para los trastornos adictivos (Lima et al., 2020; Lippi, Henry, Bovo \& Sanchis, 2020).

Por ello, se manifiesta que el confinamiento y el aislamiento actúan como solución y problema al mismo tiempo, al suponer medidas que implican la experiencia poco frecuente y desagradable de la separación de amigos y familiares, y la limitación o prohibición de muchas actividades cotidianas (trabajo, ocio, escuelas, deporte...) (Usher, Bhullar \& Jackson, 2020). Aunque todas las personas corren el riesgo de sufrir daños físicos y psicológicos como consecuencia del aislamiento, ello se agrava en personas que, por sus características sociales y personales, son más vulnerables. Según la literatura reciente, estos grupos más vulnerables a los efectos del aislamiento y confinamiento son los menores y adolescentes, las personas mayores, las personas con un nivel socioeconómico más bajo, las minorías étnicas, personas sin hogar, las mujeres víctimas de maltrato y las personas con problemas de salud mental previos (Usher et al., 2020; Yang et al., 2020). Igualmente convendría considerar de cara al futuro a las personas desempleadas y a las personas estigmatizadas por tener o haber tenido COVID-19

En este contexto, las consecuencias para la salud pública y los trastornos adictivos debido al confinamiento y a la distancia social son todavía difíciles de dimensionar, como también lo son las consecuencias a nivel orgánico que afectan principalmente al sistema respiratorio (NIDA, 2020). Sin embargo, ya existe literatura emergente que nos ofrece pistas sobre lo que está sucediendo.

El objetivo de este trabajo es presentar una revisión de la literatura científica incipiente sobre la pandemia causada por la COVID-19 y la influencia que ésta pueda tener en el ámbito de las adicciones.

\section{Método}

La revisión se realizó siguiendo cuatro etapas: identificación, cribado, elegibilidad e inclusión. Para la primera etapa de identificación, llevamos a cabo la búsqueda en la base de datos Web of Science (WoS) en su modalidad "todas las bases de datos» (Web of Science Core Collection, Korean Journal Database, Current Contents Conect, Derwent Innovation Index, Medline y Scielo), estableciendo una restricción temporal a los artículos publicados hasta mayo de 2020. Diseñamos una ecuación de búsqueda que incluye los siguientes términos relacionados con trastornos adictivos: "alcohol", OR "cocaine" OR "stimulant*" OR "tobacco" OR "nicotine" OR "benzo*" OR "opioid*" OR "marihuana" OR "cannabis" OR "marijuana" OR "gaming" OR "gambling" OR "pathological gambling" OR "addiction*" OR "addictiv*" OR "drug use" OR "drug abuse" OR "drug dependenc*" OR "substance abuse", combinados mediante el booleano AND con los siguientes términos referentes al COVID-19: covid-19 OR "covid 19" OR coronavirus* OR "SARS-CoV-2". De manera complementaria, se realizó una búsqueda a través de la revisión de las referencias utilizadas por los artículos seleccionados. 
En la etapa de cribado, los criterios de inclusión que aplicamos fueron: a) aparición de alguno de los términos de búsqueda en el título, resumen o palabras claves y b) trabajos a los que pudiéramos tener acceso completo, c) cualquier tipo de documento (article, review, editorial, letter, early access, abstract y unspecified), y d) trabajos en inglés o español.

En la etapa de elegibilidad aplicamos dos criterios de exclusión: que no tratase la temática de adicciones en relación con la COVID-19 y que fueran publicados con anterioridad al año 2020. Tras la aplicación de este criterio, el número de documentos seleccionados fue 38.

Buscamos información referente a las siguientes variables: tipo de problemática a la que aluden los autores, conclusiones a las que llegan y propuestas de actuación.

En la Figura 1 presentamos el número de trabajos incluidos en cada etapa del proceso de búsqueda y selección de trabajos.

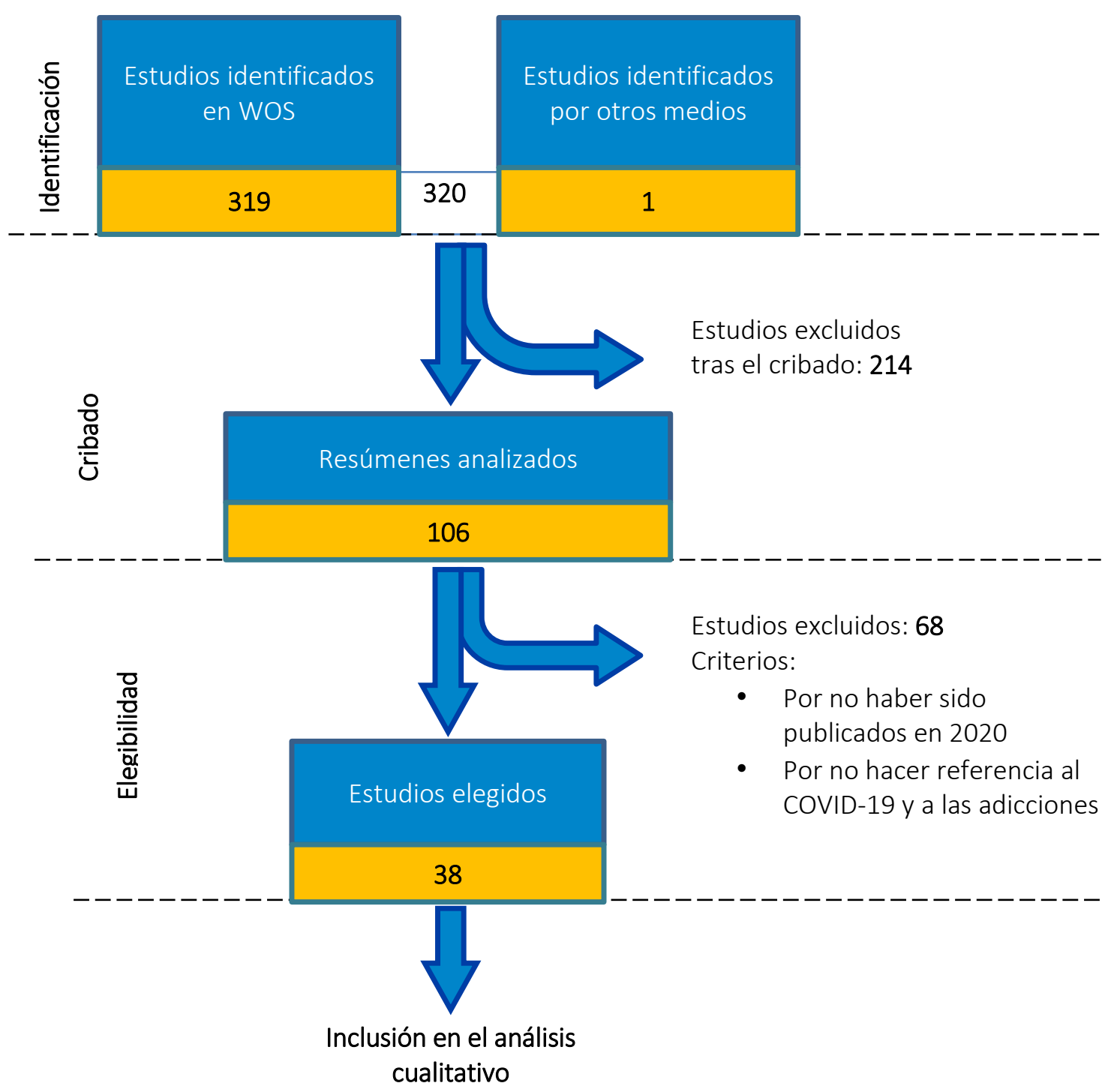

Figura 1. Diagrama de trabajos incluidos en cada etapa del proceso de búsqueda "COVID-19 y adicciones"

\section{Resultados}


Lo primero que nos muestran los documentos seleccionados y analizados es que la tipología de la mayoría (76\%) corresponde a «editoriales», «cartas al director», «comentarios», "puntos de vista» etc. Es decir, en general presentan opiniones basadas en literatura emergente desde diferentes perspectivas de la problemática de la COVID-19, y su relación con las adicciones. Aunque lógicamente todavía es pronto para contar con un mayor volumen de investigaciones más completas, los documentos analizados ofrecen una tendencia que indica donde pueden estar los primeros focos de interés. En la Tabla 1 podemos observar un resumen de los trabajos analizados.

Tabla 1

Resumen de trabajos analizados

\begin{tabular}{|c|c|c|c|c|c|c|}
\hline Primer autor & País & Documento & Tipo de adicción & Problemática & Conclusiones & Propuestas \\
\hline Sherman, L. & EE.UU. & Artículo original & Alcohol & $\begin{array}{l}\text { Ansiedad } \\
\text { disfuncional } \\
\text { asociada con la } \\
\text { crisis del COVID-19. } \\
\text { Se presenta la } \\
\text { herramienta } \\
\text { Coronavirus } \\
\text { anxiety scale (CAS) }\end{array}$ & $\begin{array}{l}\text { Se detecta un } \\
\text { peor diagnóstico } \\
\text { de coronavirus, } \\
\text { aumento de } \\
\text { consumo de } \\
\text { alcohol y otras } \\
\text { drogas, } \\
\text { incapacidad } \\
\text { extrema e } \\
\text { ideación suicida }\end{array}$ & $\begin{array}{l}\text { Utilización del CAS } \\
\text { para detectar } \\
\text { posibles } \\
\text { situaciones de } \\
\text { ansiedad derivadas } \\
\text { de las crisis del } \\
\text { COVID-19 }\end{array}$ \\
\hline Ahmed, M. & China & Artículo original & Alcohol & $\begin{array}{l}\text { Disminución de la } \\
\text { salud mental en la } \\
\text { población debido a } \\
\text { la crisis del COVID- } \\
19\end{array}$ & $\begin{array}{l}\text { Se concluye un } \\
\text { aumento de la } \\
\text { ansiedad, } \\
\text { depresión, } \\
\text { consumo de } \\
\text { alcohol y una } \\
\text { menor ratio de } \\
\text { bienestar en } \\
\text { general sobre } \\
\text { todo en personas } \\
\text { entre } 21-40 \text { años }\end{array}$ & $\begin{array}{l}\text { Promoción de } \\
\text { equipos de salud } \\
\text { mental } \\
\text { multidisciplinares, } \\
\text { ampliación de } \\
\text { tratamientos } \\
\text { psiquiátricos y } \\
\text { otros servicios de } \\
\text { salud mental y uso } \\
\text { de plataformas en } \\
\text { línea }\end{array}$ \\
\hline $\begin{array}{l}\text { Shalbafan, } \\
\text { M. }\end{array}$ & Irán & Carta al editor & Alcohol & $\begin{array}{l}\text { Aumento de } \\
\text { consumo de } \\
\text { alcohol debido a la } \\
\text { creencia de que } \\
\text { previene el COVID- } \\
19\end{array}$ & $\begin{array}{l}\text { Se alerta sobre } \\
\text { que la } \\
\text { desinformación } \\
\text { que hay en Irán } \\
\text { sobre el alcohol } \\
\text { provocó la } \\
\text { expansión de la } \\
\text { creencia de que } \\
\text { el alcohol es } \\
\text { bueno para el } \\
\text { virus. Esto } \\
\text { provocó } \\
\text { intoxicaciones y } \\
\text { muertes }\end{array}$ & $\begin{array}{l}\text { Aumento urgente } \\
\text { de la información } \\
\text { verídica y } \\
\text { contrastada sobre } \\
\text { el alcohol y el } \\
\text { coVID-19 }\end{array}$ \\
\hline Reynolds, J. & $\begin{array}{l}\text { Australia } \\
\text { y R.U. }\end{array}$ & Comentario & Alcohol & $\begin{array}{l}\text { Venta de alcohol } \\
\text { en tiendas para } \\
\text { consumo fuera de } \\
\text { las instalaciones }\end{array}$ & $\begin{array}{l}\text { Se alerta sobre } \\
\text { un posible } \\
\text { aumento de } \\
\text { consumo de } \\
\text { alcohol en los } \\
\text { hogares }\end{array}$ & $\begin{array}{l}\text { Revisión de este } \\
\text { tipo de licencias }\end{array}$ \\
\hline
\end{tabular}




\begin{tabular}{|c|c|c|c|c|c|c|}
\hline Clay, J. & $\mathrm{N} / \mathrm{A}$ & Correspondencia & Alcohol & $\begin{array}{l}\text { Posible aumento } \\
\text { del consumo de } \\
\text { alcohol debido al } \\
\text { confinamiento }\end{array}$ & $\begin{array}{l}\text { Aunque las } \\
\text { consecuencias } \\
\text { del aislamiento } \\
\text { son todavía } \\
\text { desconocidas, se } \\
\text { llama la atención } \\
\text { sobre un posible } \\
\text { aumento de } \\
\text { estrés, } \\
\text { impulsividad y } \\
\text { recaídas }\end{array}$ & $\begin{array}{l}\text { Ofrecimiento de } \\
\text { más recursos de } \\
\text { adicciones y } \\
\text { servicios de salud } \\
\text { en general antes y } \\
\text { después de la } \\
\text { pandemia }\end{array}$ \\
\hline $\begin{array}{l}\text { García- } \\
\text { Álvarez, L. }\end{array}$ & España & Editorial & Alcohol y tabaco & $\begin{array}{l}\text { Repaso de las } \\
\text { consecuencias } \\
\text { negativas } \\
\text { colaterales } \\
\text { derivadas del } \\
\text { COVID-19 } \\
\text { relacionadas sobre } \\
\text { todo con salud } \\
\text { mental y } \\
\text { adicciones }\end{array}$ & $\begin{array}{l}\text { Se llama la } \\
\text { atención sobre } \\
\text { todo sobre el } \\
\text { alcohol y el } \\
\text { tabaco y el } \\
\text { impacto que } \\
\text { pueden tener } \\
\text { estás sustancias } \\
\text { en el deterioro } \\
\text { de la salud en la } \\
\text { situación de crisis } \\
\text { por el COVID-19 }\end{array}$ & $\begin{array}{l}\text { Evaluación de las } \\
\text { alteraciones } \\
\text { emocionales y } \\
\text { comportamentales, } \\
\text { fortalecimiento de } \\
\text { la salud mental y la } \\
\text { atención } \\
\text { psicosocial }\end{array}$ \\
\hline Reece, A. S. & EE.UU. & Artículo original & Cannabis & $\begin{array}{l}\text { Posible relación } \\
\text { entre un alto } \\
\text { consumo de } \\
\text { cannabis y mayores } \\
\text { tasas de infección } \\
\text { por coronavirus }\end{array}$ & $\begin{array}{l}\text { Se confirma su } \\
\text { hipótesis de que } \\
\text { las zonas donde } \\
\text { se detecta mayor } \\
\text { consumo de } \\
\text { cannabis hay } \\
\text { mayores tasas de } \\
\text { infección }\end{array}$ & $\begin{array}{l}\text { Más investigación } \\
\text { al respecto y } \\
\text { controles de } \\
\text { cannabis más } \\
\text { estrictos como una } \\
\text { medida de salud } \\
\text { pública para } \\
\text { abordar el desafío } \\
\text { del virus }\end{array}$ \\
\hline Sexton, $M$. & EE.UU. & Artículo original & Cannabis & $\begin{array}{l}\text { Reflexión sobre el } \\
\text { papel del cannabis } \\
\text { y sus componentes } \\
\text { en el contexto de } \\
\text { la pandemia } \\
\text { COVID-19 }\end{array}$ & $\begin{array}{l}\text { Se hace un } \\
\text { balance sobre los } \\
\text { posibles efectos } \\
\text { negativos y } \\
\text { positivos del } \\
\text { cannabis y } \\
\text { componentes } \\
\text { como el THC } \\
\text { (principio activo } \\
\text { más potente y } \\
\text { más asociado a } \\
\text { efectos } \\
\text { negativos) y el } \\
\text { CBD (sin apenas } \\
\text { potencial adictivo } \\
\text { y posible } \\
\text { candidato como } \\
\text { potencial } \\
\text { tratamiento por } \\
\text { sus efectos } \\
\text { antiinflamatorios) }\end{array}$ & $\begin{array}{l}\text { Enfoques } \\
\text { individualizados } \\
\text { por parte de los } \\
\text { profesionales de la } \\
\text { salud para evaluar } \\
\text { al paciente, } \\
\text { incluida la salud } \\
\text { respiratoria y } \\
\text { cardiovascular o la } \\
\text { inmunodeficiencia } \\
\text { existente }\end{array}$ \\
\hline King, D. & Australia & Carta al editor & $\begin{array}{l}\text { Juego } \\
\text { patológico } \\
\text { (gaming) }\end{array}$ & $\begin{array}{l}\text { Destaca la alta } \\
\text { presencia de los } \\
\text { videojuegos } \\
\text { durante el } \\
\text { confinamiento. }\end{array}$ & $\begin{array}{l}\text { Es necesario } \\
\text { establecer un } \\
\text { balance } \\
\text { equilibrado, } \\
\text { sobre todo para } \\
\text { la población más } \\
\text { joven, entre el }\end{array}$ & $\begin{array}{l}\text { Diseñar y } \\
\text { promover } \\
\text { enfoques } \\
\text { equilibrados y } \\
\text { efectivos para los } \\
\text { juegos durante la } \\
\text { pandemia de }\end{array}$ \\
\hline
\end{tabular}




\begin{tabular}{|c|c|c|c|c|c|c|}
\hline & & & & & $\begin{array}{l}\text { juego como } \\
\text { elemento } \\
\text { positivo de } \\
\text { entretenimiento } \\
\text { y abuso del } \\
\text { mismo, debido a } \\
\text { las alteraciones } \\
\text { que puede } \\
\text { conllevar (sueño, } \\
\text { concentración, } \\
\text { etc.) }\end{array}$ & $\begin{array}{l}\text { COVID-19 para } \\
\text { apoyar el bienestar } \\
\text { físico y psicológico }\end{array}$ \\
\hline Derek, D. & EE.UU. & Editorial & General & $\begin{array}{l}\text { Alerta sobre un } \\
\text { posible aumento } \\
\text { de consumo como } \\
\text { alcohol, tabaco, } \\
\text { cannabis, } \\
\text { benzodiacepinas y } \\
\text { opiodes entre la } \\
\text { población de riesgo } \\
\text { que son los } \\
\text { mayores de } 65 \\
\text { años }\end{array}$ & $\begin{array}{l}\text { El aumento de } \\
\text { conductas } \\
\text { adictivas en las } \\
\text { personas } \\
\text { mayores requiere } \\
\text { especial atención } \\
\text { como colectivo } \\
\text { vulnerable ante } \\
\text { la situación de } \\
\text { covID-19 }\end{array}$ & $\begin{array}{l}\text { Más estudios que } \\
\text { profundicen sobre } \\
\text { la realidad } \\
\text { concreta de este } \\
\text { colectivo }\end{array}$ \\
\hline $\begin{array}{l}\text { Rolim-Lima, } \\
\text { N. }\end{array}$ & $\mathrm{N} / \mathrm{A}$ & Carta al editor & General & $\begin{array}{l}\text { Llamada de } \\
\text { atención sobre las } \\
\text { personas sin hogar } \\
\text { ante el COVID-19 }\end{array}$ & $\begin{array}{l}\text { Se alerta de la } \\
\text { situación de } \\
\text { especial } \\
\text { vulnerabilidad de } \\
\text { las personas sin } \\
\text { hogar que } \\
\text { duermen en la } \\
\text { calle y que tienen } \\
\text { problemas de } \\
\text { adicciones }\end{array}$ & $\begin{array}{l}\text { Mantenimiento y } \\
\text { promoción de } \\
\text { servicios } \\
\text { sociosanitarios } \\
\text { dirigidos a } \\
\text { personas sin hogar }\end{array}$ \\
\hline Dunlop, A. & Australia & Opinión & General & $\begin{array}{l}\text { Destaca la } \\
\text { necesidad de } \\
\text { garantizar e incluso } \\
\text { ampliar la oferta } \\
\text { de servicios } \\
\text { sociosanitarios } \\
\text { para personas } \\
\text { consumidoras } \\
\text { durante la } \\
\text { pandemia de } \\
\text { CovID-19 }\end{array}$ & $\begin{array}{l}\text { Por el carácter } \\
\text { vulnerable de } \\
\text { esta población } \\
\text { (personas } \\
\text { mayores, sin } \\
\text { hogar, inmuno } \\
\text { deprimidas, etc.), } \\
\text { los servicios de } \\
\text { salud deben } \\
\text { adaptarse a sus } \\
\text { necesidades y } \\
\text { garantizar su } \\
\text { asistencia }\end{array}$ & $\begin{array}{l}\text { Cambios en el } \\
\text { modelo de } \\
\text { tratamiento de } \\
\text { atención para } \\
\text { facilitar el } \\
\text { distanciamiento } \\
\text { social. }\end{array}$ \\
\hline Volkow, N. & EE.UU. & $\begin{array}{l}\text { Ideas y } \\
\text { opiniones }\end{array}$ & General & $\begin{array}{l}\text { Aumento del riesgo } \\
\text { de colisión entre } \\
\text { las personas con } \\
\text { adicciones y el } \\
\text { COVID-19 }\end{array}$ & $\begin{array}{l}\text { Se alerta sobre } \\
\text { las consecuencias } \\
\text { negativas del } \\
\text { COVID-19 desde } \\
\text { distintos ángulos } \\
\text { para las personas } \\
\text { con adicciones } \\
\text { (peor pronóstico, } \\
\text { aumento de } \\
\text { consumo, falta } \\
\text { de recursos...) }\end{array}$ & $\begin{array}{l}\text { Mantenimiento de } \\
\text { programas y } \\
\text { tratamientos y } \\
\text { aumento de } \\
\text { recursos }\end{array}$ \\
\hline
\end{tabular}




\begin{tabular}{|c|c|c|c|c|c|c|}
\hline Lippi, G. & $\mathrm{N} / \mathrm{A}$ & $\begin{array}{l}\text { Artículo de } \\
\text { opinión }\end{array}$ & General & $\begin{array}{l}\text { Aumento de la } \\
\text { inactividad física, } \\
\text { ganancia de peso, } \\
\text { aumento de las } \\
\text { adicciones } \\
\text { comportamentales, } \\
\text { aislamiento, poca } \\
\text { luz solar }\end{array}$ & $\begin{array}{l}\text { Se destacan } \\
\text { consecuencias } \\
\text { como la } \\
\text { osteoporosis, } \\
\text { diabetes, } \\
\text { enfermedades } \\
\text { cardiovasculares, } \\
\text { desórdenes } \\
\text { psicológicos, } \\
\text { complicaciones } \\
\text { neurológicas, } \\
\text { depresión, } \\
\text { ansiedad, falta de } \\
\text { vitamina D }\end{array}$ & $\begin{array}{l}\text { Recomendación de } \\
\text { más ejercicio, } \\
\text { dietas } \\
\text { hipocalóricas, } \\
\text { control del uso de } \\
\text { aparatos } \\
\text { electrónicos y } \\
\text { control del tiempo } \\
\text { de uso de los } \\
\text { mismos, desarrollo } \\
\text { personal y } \\
\text { mantenimiento de } \\
\text { los contactos }\end{array}$ \\
\hline Marsden, J. & $\begin{array}{l}\text { Reino } \\
\text { Unido }\end{array}$ & Editorial & General & $\begin{array}{l}\text { Descripción de las } \\
\text { amenazas } \\
\text { particulares para } \\
\text { personas con } \\
\text { trastornos } \\
\text { adictivos en } \\
\text { relación a la } \\
\text { pandemia }\end{array}$ & $\begin{array}{l}\text { Se describen las } \\
\text { consecuencias } \\
\text { negativas } \\
\text { focalizadas en } \\
\text { diferentes } \\
\text { sustancias }\end{array}$ & $\begin{array}{l}\text { Aprendizaje mutuo } \\
\text { entre países sobre } \\
\text { los problemas } \\
\text { encontrados y las } \\
\text { soluciones } \\
\text { propuestas, } \\
\text { coordinación entre } \\
\text { las agencias } \\
\text { supranacionales }\end{array}$ \\
\hline Arya, S. & India & Carta al editor & $\begin{array}{l}\text { General / } \\
\text { alcohol }\end{array}$ & $\begin{array}{l}\text { Alerta ante la } \\
\text { posible falta o } \\
\text { disminución de } \\
\text { recursos para salud } \\
\text { mental y } \\
\text { adicciones }\end{array}$ & $\begin{array}{l}\text { Se destaca la } \\
\text { dificultad de } \\
\text { acceso a los } \\
\text { servicios de salud } \\
\text { y de seguimiento } \\
\text { de los } \\
\text { tratamientos. } \\
\text { Una } \\
\text { consecuencia es } \\
\text { el alcohol hecho } \\
\text { en casa debido a } \\
\text { la abstinencia }\end{array}$ & $\begin{array}{l}\text { Fomento de las } \\
\text { herramientas de } \\
\text { salud a distancia } \\
\text { ("telehealth") }\end{array}$ \\
\hline Kar, S. & N/A & Carta al editor & $\begin{array}{l}\text { General / } \\
\text { alcohol }\end{array}$ & $\begin{array}{l}\text { Aumento } \\
\text { generalizado de } \\
\text { todas las conductas } \\
\text { adictivas debido a } \\
\text { las medidas de } \\
\text { prevención ante la } \\
\text { pandemia }\end{array}$ & $\begin{array}{l}\text { Se alerta sobre } \\
\text { un uso abusivo } \\
\text { de aparatos } \\
\text { electrónicos } \\
\text { debido al } \\
\text { confinamiento, } \\
\text { interrupciones en } \\
\text { tratamientos con } \\
\text { agonistas debido } \\
\text { a otras } \\
\text { prioridades del } \\
\text { sistema sanitario, } \\
\text { abstinencia que } \\
\text { puede llevar a } \\
\text { fabricación en } \\
\text { casa de bebidas } \\
\text { alcohólicas }\end{array}$ & $\begin{array}{l}\text { Sensibilización a la } \\
\text { sociedad sobre los } \\
\text { problemas } \\
\text { relacionados con } \\
\text { las adicciones } \\
\text { durante esta } \\
\text { pandemia, } \\
\text { fortalecimiento de } \\
\text { los servicios de } \\
\text { salud mental, una } \\
\text { especial atención a } \\
\text { los jóvenes }\end{array}$ \\
\hline Carrico, A. W. & EE.UU. & Notas de campo & Metanfetamina & $\begin{array}{l}\text { Aumento del riesgo } \\
\text { de la infección por } \\
\text { coronavirus de las } \\
\text { personas con VIH } \\
\text { que además son } \\
\text { consumidoras de } \\
\text { metanfetamina }\end{array}$ & $\begin{array}{l}\text { Se llama la } \\
\text { atención sobre la } \\
\text { situación de estas } \\
\text { personas, que, } \\
\text { con un sistema } \\
\text { inmunológico } \\
\text { debilitado por } \\
\text { VIH y el consumo }\end{array}$ & $\begin{array}{l}\text { Gestión sostenida y } \\
\text { coordinada, llevar } \\
\text { a cabo una } \\
\text { respuesta que } \\
\text { integre enfoques } \\
\text { conductuales y } \\
\text { biomédicos, tal y } \\
\text { como se lleva }\end{array}$ \\
\hline
\end{tabular}




\begin{tabular}{|c|c|c|c|c|c|c|}
\hline & & & & & $\begin{array}{l}\text { de } \\
\text { metanfetamina. } \\
\text { Recalcan que, si } \\
\text { además se realiza } \\
\text { el consumo por } \\
\text { vía fumada, } \\
\text { puede afectar } \\
\text { directamente al } \\
\text { sistema } \\
\text { respiratorio }\end{array}$ & $\begin{array}{l}\text { haciendo desde } \\
\text { hace tres décadas } \\
\text { con el VIH / SIDA }\end{array}$ \\
\hline Jenkins, W. & EE.UU. & Comentario & Opioides & $\begin{array}{l}\text { Posible aumento } \\
\text { de consumo de } \\
\text { opiáceos en } \\
\text { contextos rurales } \\
\text { y/o aislados }\end{array}$ & $\begin{array}{l}\text { Se detecta la } \\
\text { posibilidad de } \\
\text { barreras a los } \\
\text { recursos } \\
\text { sociosanitarios y } \\
\text { a la información } \\
\text { verídica sobre el } \\
\text { covID-19 }\end{array}$ & $\begin{array}{l}\text { Acceso a } \\
\text { información creíble } \\
\text { contrastada y } \\
\text { fortalecer el acceso } \\
\text { a los recursos }\end{array}$ \\
\hline Vecchio, S. & Italia & $\begin{array}{l}\text { Comunicación } \\
\text { breve }\end{array}$ & Opioides & $\begin{array}{l}\text { Llamada de } \\
\text { atención sobre las } \\
\text { personas } \\
\text { consumidoras de } \\
\text { opioides frente al } \\
\text { contexto de } \\
\text { COVID-19 }\end{array}$ & $\begin{array}{l}\text { Por su carácter } \\
\text { más vulnerable } \\
\text { en distintos } \\
\text { aspectos } \\
\text { (situación de } \\
\text { marginalidad, } \\
\text { peores } \\
\text { condiciones de } \\
\text { salud física y } \\
\text { psicológica, } \\
\text { estigma, etc.) } \\
\text { este colectivo } \\
\text { deber tener una } \\
\text { especial } \\
\text { protección }\end{array}$ & $\begin{array}{l}\text { Apuesta por } \\
\text { estrategias de } \\
\text { reducción del } \\
\text { daño, aumento de } \\
\text { protocolos } \\
\text { relacionados con el } \\
\text { acceso a recursos } \\
\text { para facilitar la } \\
\text { higiene, aumento } \\
\text { de atención } \\
\text { telefónica o por } \\
\text { videollamada, } \\
\text { proveer } \\
\text { información veraz } \\
\text { y contrastada tanto } \\
\text { sobre el virus como } \\
\text { sobre servicios } \\
\text { disponibles. }\end{array}$ \\
\hline Wilson, C. & EE.UU. & Comentario & Opioides & $\begin{array}{l}\text { Llamada de } \\
\text { atención sobre las } \\
\text { personas sin hogar } \\
\text { ante el COVID-19 }\end{array}$ & $\begin{array}{l}\text { Se destaca la } \\
\text { situación de } \\
\text { vulnerabilidad de } \\
\text { las personas sin } \\
\text { hogar } \\
\text { consumidoras de } \\
\text { opioides y se } \\
\text { reclama una } \\
\text { especial } \\
\text { protección para } \\
\text { evitar la } \\
\text { propagación del } \\
\text { coviD-19 en este } \\
\text { colectivo }\end{array}$ & $\begin{array}{l}\text { Mantenimiento de } \\
\text { tratamientos en } \\
\text { general }\end{array}$ \\
\hline Wakeman, S. & EE.UU. & Comentario & Opioides & $\begin{array}{l}\text { Alerta sobre las } \\
\text { consecuencias } \\
\text { negativas para las } \\
\text { personas } \\
\text { consumidoras de } \\
\text { opioides en la } \\
\text { situación de } \\
\text { COVID-19 }\end{array}$ & $\begin{array}{l}\text { Se pone el foco } \\
\text { en la necesidad } \\
\text { de adaptar tanto } \\
\text { el tratamiento } \\
\text { como la } \\
\text { dispensación de } \\
\text { los mismos al } \\
\text { contexto del } \\
\text { coviD-19 para } \\
\text { que no haya un }\end{array}$ & $\begin{array}{l}\text { Utilizar la crisis } \\
\text { como una } \\
\text { oportunidad para } \\
\text { crear un sistema } \\
\text { de salud que } \\
\text { aborde las } \\
\text { necesidades de las } \\
\text { personas } \\
\text { vulnerables, como } \\
\text { las que sufren }\end{array}$ \\
\hline
\end{tabular}




\begin{tabular}{|c|c|c|c|c|c|c|}
\hline & & & & & $\begin{array}{l}\text { choque entre } \\
\text { ambas } \\
\text { problemáticas }\end{array}$ & $\begin{array}{l}\text { trastorno por uso } \\
\text { de opioides }\end{array}$ \\
\hline Becker, W. & EE.UU. & $\begin{array}{l}\text { Ideas y } \\
\text { opiniones }\end{array}$ & Opioides & $\begin{array}{l}\text { Colisión de la crisis } \\
\text { de los opioides y la } \\
\text { crisis del COVID-10 } \\
\text { en EE.UU. }\end{array}$ & $\begin{array}{l}\text { Se alerta sobre la } \\
\text { posibilidad de un } \\
\text { aumento de } \\
\text { consumo y de la } \\
\text { vulnerabilidad } \\
\text { entre los } \\
\text { consumidores de } \\
\text { opioides no } \\
\text { preescritos }\end{array}$ & $\begin{array}{l}\text { Acceso } \\
\text { ininterrumpido a la } \\
\text { metadona y la } \\
\text { buprenorfina }\end{array}$ \\
\hline Sun, Y. & China & Editorial & Opioides & $\begin{array}{l}\text { Focalización en las } \\
\text { personas con una } \\
\text { adicción a opioides } \\
\text { durante el COVID- } \\
19\end{array}$ & $\begin{array}{l}\text { Se alerta sobre la } \\
\text { posible } \\
\text { desatención que } \\
\text { puede vivir este } \\
\text { colectivo y las } \\
\text { consecuencias } \\
\text { que conllevaría } \\
\text { (recaídas, } \\
\text { aumento del } \\
\text { consumo...) }\end{array}$ & $\begin{array}{l}\text { Planificar los } \\
\text { servicios sanitarios } \\
\text { para no dejar sin } \\
\text { tratamiento ni } \\
\text { disminuirlo a estas } \\
\text { personas }\end{array}$ \\
\hline Alexander, $\mathrm{C}$. & EE.UU. & $\begin{array}{l}\text { Ideas y } \\
\text { opiniones }\end{array}$ & Opioides & $\begin{array}{l}\text { Llamada de } \\
\text { atención sobre las } \\
\text { personas } \\
\text { consumidoras de } \\
\text { opioides y su } \\
\text { acceso al } \\
\text { tratamiento }\end{array}$ & $\begin{array}{l}\text { Se destaca la } \\
\text { necesidad de } \\
\text { garantizar el } \\
\text { acceso al } \\
\text { tratamiento } \\
\text { farmacológico y } \\
\text { psicosocial de } \\
\text { estas personas, } \\
\text { para que no } \\
\text { experimenten } \\
\text { retroceso en su } \\
\text { recuperación }\end{array}$ & $\begin{array}{l}\text { Planificación y el } \\
\text { apoyo para limitar } \\
\text { la interrupción de } \\
\text { los Nuevos } \\
\text { esfuerzos e } \\
\text { innovaciones, } \\
\text { como el uso sin } \\
\text { precedentes de la } \\
\text { tecnología para } \\
\text { suplir el cara a cara }\end{array}$ \\
\hline Green, T. C. & EE.UU. & Editorial & Opioides & $\begin{array}{l}\text { Llamada de } \\
\text { atención sobre las } \\
\text { personas } \\
\text { consumidoras de } \\
\text { opioides y su } \\
\text { acceso al } \\
\text { tratamiento }\end{array}$ & $\begin{array}{l}\text { Se recalca la } \\
\text { importancia del } \\
\text { acceso al } \\
\text { tratamiento de } \\
\text { las personas } \\
\text { consumidoras de } \\
\text { opioides y se } \\
\text { advierte de las } \\
\text { consecuencias } \\
\text { negativas si esto } \\
\text { no se cumple }\end{array}$ & $\begin{array}{l}\text { Directrices y } \\
\text { recomendaciones } \\
\text { para eliminar las } \\
\text { restricciones en la } \\
\text { atención y el } \\
\text { estigma asociado } \\
\text { experimentado por } \\
\text { las personas } \\
\text { consumidoras de } \\
\text { sustancias }\end{array}$ \\
\hline Vardavas, C. & China & Revisión & Tabaco & $\begin{array}{l}\text { Relación de fumar } \\
\text { con una peor } \\
\text { progresión de la } \\
\text { enfermedad } \\
\text { COVID-19 }\end{array}$ & $\begin{array}{l}\text { Se puede intuir } \\
\text { que fumar está } \\
\text { asociado con una } \\
\text { progresión } \\
\text { negativa del } \\
\text { cOVID-19 }\end{array}$ & $\begin{array}{l}\text { Al ser una revisión, } \\
\text { no hacen } \\
\text { propuestas } \\
\text { concretas }\end{array}$ \\
\hline Tindle, $\mathrm{H}$. & N/A & Carta & Tabaco & $\begin{array}{l}\text { Comentan la idea, } \\
\text { aun no confirmada, } \\
\text { de que la nicotina } \\
\text { medicinal puede }\end{array}$ & $\begin{array}{l}\text { Es necesario } \\
\text { profundizar más } \\
\text { sobre los posibles } \\
\text { beneficios de la }\end{array}$ & $\begin{array}{l}\text { Más investigación } \\
\text { para confirmar o } \\
\text { desmentir estas } \\
\text { propuestas }\end{array}$ \\
\hline
\end{tabular}




\begin{tabular}{|c|c|c|c|c|c|c|}
\hline & & & & $\begin{array}{l}\text { tener efectos } \\
\text { positivos para el } \\
\text { tratamiento del } \\
\text { COVID-19 }\end{array}$ & $\begin{array}{l}\text { nicotina para } \\
\text { fines } \\
\text { terapéuticos y su } \\
\text { relación con el } \\
\text { COVID-19 }\end{array}$ & \\
\hline Farsalinos, $\mathrm{K}$. & China & Metaanálisis & Tabaco & $\begin{array}{l}\text { Se pretende arrojar } \\
\text { claridad sobre el } \\
\text { efecto que tiene la } \\
\text { nicotina sobre las } \\
\text { personas } \\
\text { infectadas por } \\
\text { coronavirus }\end{array}$ & $\begin{array}{l}\text { Los resultados } \\
\text { sugieren que } \\
\text { fumar no ha sido } \\
\text { un factor de } \\
\text { riesgo para las } \\
\text { personas } \\
\text { hospitalizadas en } \\
\text { China por COVID- } \\
19\end{array}$ & $\begin{array}{l}\text { Recomiendan } \\
\text { cautela y más } \\
\text { investigación al } \\
\text { respecto sobre los } \\
\text { posibles efectos } \\
\text { beneficiosos de la } \\
\text { nicotina }\end{array}$ \\
\hline $\begin{array}{l}\text { Da Silva } \\
\text { Leonel, A. }\end{array}$ & $\mathrm{N} / \mathrm{A}$ & Carta al editor & Tabaco & $\begin{array}{l}\text { Hace hincapié en la } \\
\text { necesidad de } \\
\text { formación de los } \\
\text { estudiantes de } \\
\text { medicina y } \\
\text { odontología sobre } \\
\text { los factores de } \\
\text { riesgo del tabaco }\end{array}$ & $\begin{array}{l}\text { Los factores de } \\
\text { riesgo para } \\
\text { diversas } \\
\text { enfermedades, } \\
\text { como el cáncer } \\
\text { de cuello, y las } \\
\text { recientes } \\
\text { complicaciones } \\
\text { asociadas con } \\
\text { CoviD-19, } \\
\text { necesitan que los } \\
\text { estudiantes estén } \\
\text { debidamente } \\
\text { formados para } \\
\text { hacerles frente }\end{array}$ & $\begin{array}{l}\text { Las universidades y } \\
\text { las asociaciones de } \\
\text { profesionales de la } \\
\text { salud, } \\
\text { especialmente } \\
\text { médicos y } \\
\text { dentales, deben } \\
\text { invertir en la } \\
\text { capacitación de los } \\
\text { estudiantes de } \\
\text { salud en relación } \\
\text { con la percepción y } \\
\text { el asesoramiento } \\
\text { de los fumadores. }\end{array}$ \\
\hline $\begin{array}{l}\text { Vashishta } \\
\text { Rinkoo, A. }\end{array}$ & India & Carta & $\begin{array}{l}\text { Tabaco/cigarrillo } \\
\text { electrónico y } \\
\text { nuez de areca }\end{array}$ & $\begin{array}{l}\text { Relación del uso de } \\
\text { tabaco sin humo y } \\
\text { la nuez de areca en } \\
\text { el contexto de } \\
\text { COVID-19, } \\
\text { productos con alta } \\
\text { prevalencia en } \\
\text { muchos países del } \\
\text { sur de Asia Oriental } \\
\text { y algunos países de } \\
\text { la zona del Pacífico } \\
\text { Occidental }\end{array}$ & $\begin{array}{l}\text { Frente a la } \\
\text { normativa poco } \\
\text { clara y } \\
\text { contradictoria } \\
\text { que se está } \\
\text { llevando a cabo } \\
\text { en los países de } \\
\text { esta zona, hacen } \\
\text { falta medidas } \\
\text { contundentes y } \\
\text { coherentes sobre } \\
\text { el consumo y } \\
\text { venta de estas } \\
\text { sustancias }\end{array}$ & $\begin{array}{l}\text { Se necesita más } \\
\text { investigación que } \\
\text { avale el peligro que } \\
\text { conlleva el } \\
\text { consumo de estas } \\
\text { sustancias en } \\
\text { relación con el } \\
\text { COVID-19 para } \\
\text { alentar políticas } \\
\text { públicas enfocadas } \\
\text { en el cese de estos } \\
\text { consumos }\end{array}$ \\
\hline Vázquez, J. & España & Carta al editor & Tabaco & $\begin{array}{l}\text { Relación de fumar } \\
\text { con una peor } \\
\text { progresión de la } \\
\text { enfermedad } \\
\text { COVID-19 }\end{array}$ & $\begin{array}{l}\text { Se sugiere que el } \\
\text { que los hombres } \\
\text { tengan un peor } \\
\text { pronóstico en la } \\
\text { enfermedad } \\
\text { puede deberse a } \\
\text { tener un patrón } \\
\text { de consumo de } \\
\text { tabaco más } \\
\text { elevado }\end{array}$ & $\begin{array}{l}\text { Consideración en } \\
\text { los mensajes de } \\
\text { salud pública de los } \\
\text { consejos } \\
\text { disponibles para } \\
\text { dejar de fumar } \\
\text { basados en la } \\
\text { evidencia científica }\end{array}$ \\
\hline
\end{tabular}




\begin{tabular}{|c|c|c|c|c|c|c|}
\hline Olds, J. & $\mathrm{N} / \mathrm{A}$ & Punto de vista & Tabaco & $\begin{array}{l}\text { Relación del } \\
\text { consumo de } \\
\text { tabaco con un peor } \\
\text { pronóstico de la } \\
\text { enfermedad } \\
\text { COVID-19 }\end{array}$ & $\begin{array}{l}\text { Se refiere que } \\
\text { fumar parece } \\
\text { participar en un } \\
\text { proceso celular } \\
\text { directo que tiene } \\
\text { efecto en la } \\
\text { infección por } \\
\text { COVID-19 y su } \\
\text { posible resultado } \\
\text { en un mecanismo } \\
\text { relacionado con } \\
\text { la habilidad de } \\
\text { los receptores } \\
\text { nicotínicos de } \\
\text { regular la } \\
\text { expresión de la } \\
\text { proteína ACE2 en } \\
\text { células }\end{array}$ & $\begin{array}{l}\text { Promoción de la } \\
\text { salud pública para } \\
\text { identificar } \\
\text { poblaciones de } \\
\text { riesgo y ayudar en } \\
\text { lugares de } \\
\text { intervención crítica }\end{array}$ \\
\hline Hefler, M. & $\mathrm{N} / \mathrm{A}$ & Editorial & Tabaco & $\begin{array}{l}\text { Relación del tabaco } \\
\text { con un peor } \\
\text { pronóstico por } \\
\text { COVID-19 }\end{array}$ & $\begin{array}{l}\text { Se cuestionan los } \\
\text { efectos negativos } \\
\text { de que las } \\
\text { tiendas donde se } \\
\text { vende tabaco se } \\
\text { mantengan } \\
\text { abiertas durante } \\
\text { la pandemia }\end{array}$ & $\begin{array}{l}\text { Petición de que se } \\
\text { replantee el que } \\
\text { las tiendas donde } \\
\text { se vende tabaco } \\
\text { estén abiertas } \\
\text { durante la } \\
\text { pandemia. Se pide } \\
\text { más apoyo en } \\
\text { salud mental y que } \\
\text { el dejar fumar se } \\
\text { considere } \\
\text { prioritario }\end{array}$ \\
\hline Cai, G. & EE.UU. & Artículo original & Tabaco & $\begin{array}{l}\text { Relación de la } \\
\text { expresión del gen } \\
\text { ACE2 con una peor } \\
\text { progresión de la } \\
\text { enfermedad } \\
\text { COVID-19 }\end{array}$ & $\begin{array}{l}\text { Se identifica la } \\
\text { regulación } \\
\text { positiva de la } \\
\text { expresión del gen } \\
\text { ACE2 pulmonar } \\
\text { en fumadores en } \\
\text { comparación con } \\
\text { los no fumadores } \\
\text { en todos los } \\
\text { conjuntos de } \\
\text { datos analizados }\end{array}$ & $\begin{array}{l}\text { Trabajo en más } \\
\text { estudios que } \\
\text { permitan conocer } \\
\text { el mecanismo } \\
\text { subyacente al } \\
\text { hecho de fumar y } \\
\text { tener peor } \\
\text { pronóstico de } \\
\text { COVID-19 }\end{array}$ \\
\hline Russo, P. & $\mathrm{N} / \mathrm{A}$ & Correspondencia & Tabaco & $\begin{array}{l}\text { Relación de fumar } \\
\text { con una peor } \\
\text { progresión de la } \\
\text { enfermedad } \\
\text { COVID-19 }\end{array}$ & $\begin{array}{l}\text { Se } \\
\text { complementan } \\
\text { las explicaciones } \\
\text { sobre el } \\
\text { mecanismo } \\
\text { celular } \\
\text { relacionado con } \\
\text { la mayor } \\
\text { expresión del gen } \\
\text { ACE2 en } \\
\text { fumadores }\end{array}$ & $\begin{array}{l}\text { No realizan } \\
\text { ninguna propuesta } \\
\text { al respecto, al } \\
\text { margen de ofrecer } \\
\text { más evidencia } \\
\text { científica }\end{array}$ \\
\hline Brake, S. & China & Editorial & Tabaco & $\begin{array}{l}\text { Relación de la } \\
\text { expresión del gen } \\
\text { ACE2 con una peor } \\
\text { progresión de la } \\
\text { enfermedad } \\
\text { COVID-19 }\end{array}$ & $\begin{array}{l}\text { Se sugiere que la } \\
\text { ACE2 está } \\
\text { regulada al alza } \\
\text { en el epitelio de } \\
\text { las vías } \\
\text { respiratorias de } \\
\text { los fumadores }\end{array}$ & $\begin{array}{l}\text { Se insta a los } \\
\text { gobiernos a que } \\
\text { actúen para } \\
\text { reducir las tasas de } \\
\text { tabaquismo en } \\
\text { todos los países ya } \\
\text { que es posible que } \\
\text { fumar exacerbe la }\end{array}$ \\
\hline
\end{tabular}


contracción, la transmisión, y mortalidad por COVID-19

Singh, A. G. India Artículo especial Tabaco / cigarrillos electrónicos

\begin{tabular}{|c|c|c|}
\hline $\begin{array}{l}\text { Relación de vapear } \\
\text { con un peor } \\
\text { pronóstico de la } \\
\text { enfermedad } \\
\text { COVID-19 }\end{array}$ & $\begin{array}{l}\text { Al igual que otros } \\
\text { productos de } \\
\text { tabaco, se } \\
\text { destaca que el } \\
\text { uso de } \\
\text { vapeadores } \\
\text { también está } \\
\text { relacionado con } \\
\text { una mayor } \\
\text { prevalencia de } \\
\text { síntomas } \\
\text { respiratorios, } \\
\text { enfermedades } \\
\text { cardíacas y } \\
\text { cánceres, todos } \\
\text { asociados con } \\
\text { coviD-19 }\end{array}$ & $\begin{array}{l}\text { Maximización de } \\
\text { las advertencias de } \\
\text { los riesgos sobre } \\
\text { todo en las } \\
\text { personas más } \\
\text { jóvenes }\end{array}$ \\
\hline
\end{tabular}

En primer lugar, encontramos publicaciones que repasan de manera más genérica las consecuencias de la COVID-19 en cuanto a las conductas adictivas, ya que nos ofrecen una visión general de algunas de las preocupaciones más destacadas (Dunlop et al., 2020; Lippi et al., 2020; Volkow, 2020). Entre ellas, el cómo puede afectar la crisis de la COVID-19 tanto por la enfermedad en sí como por las medidas de prevención tomadas, así como la necesidad de mantener los tratamientos vigentes y de prestar atención a colectivos especialmente vulnerables. Sin embargo, la lectura del total de los documentos arroja una realidad, y es que hay tres problemáticas que sobresalen por encima del resto que se refieren a tres consumos: tabaco, opioides y alcohol. A continuación, haremos una distinción entre las distintas conductas adictivas detectadas.

\section{Opioides}

En el caso de los opioides, la preocupación se focaliza tanto en el consumo de sustancias ilegales que contienen este compuesto, como al consumo de fármacos opioides que se dispensan sin prescripción médica, un tipo de consumo tan extendido en EE.UU. que es considerado una epidemia. En el caso de este último, Becker \& Fiellin (2019), alertan de la «colisión» de estas dos crisis, la derivada de la COVID-19 y la inmediatamente anterior del consumo de opioides. A este respecto, también se argumenta que las epidemias afectan en general en mayor medida a las personas que sufren situaciones de marginalidad y estigma, que además tienen afecciones psiquiátricas comórbidas, por lo que se alerta sobre la desatención que puede vivir este colectivo y las consecuencias que conllevaría (recaídas, aumento del consumo, etc.) (Lippi et al., 2020; Vecchio et al., 2020; Wakeman, Green \& Rich, 2020). Otros autores se manifiestan en una línea parecida, aunque añadiendo el agravante de encontrarse en zonas rurales aisladas, ya que cuanto más distantes estén las poblaciones, aunque exista menos probabilidad de expansión del virus, también hay más barreras en el acceso a los recursos (Jenkins et al., 2020; Wilson, Ramage \& Fagan, 2020). 


\section{Alcohol}

En el caso del alcohol, Clay \& Parker (2020) refieren que las consecuencias del aislamiento son todavía desconocidas, pero destacan el posible papel del estrés como factor de riesgo. En condiciones normales, en un contexto de no aislamiento ni confinamiento, el estrés puede ser un potencial detonante tanto para el inicio como para el mantenimiento del consumo problemático de alcohol. De la misma manera, el consumo crónico de alcohol produce neuroadaptaciones en las vías de estrés y recompensa, que conducen a ejes disfuncionales caracterizados por una desregulación de la respuesta al cortisol y déficits en la regulación emocional. Basándose en estudios previos llevados a cabo en animales, donde se demuestra que un aislamiento social a largo plazo incrementa los niveles de estrés, estos autores sugieren que un patrón parecido podría darse en humanos, convirtiendo la convergencia de los factores alcohol - aislamiento estrés en un potente factor de riesgo. Por otro lado, un reciente estudio llevado a cabo en China con el objetivo de averiguar los problemas psicológicos asociados a la situación derivada de la COVID-19 y del aislamiento masivo, concluye que existe un aumento de la tasa de ansiedad y depresión, un consumo de alcohol peligroso y dañino, y una relación de bienestar mental inferior a la habitual. Según este estudio, la franja de edad más afectada en términos de salud mental y consumo de alcohol es la de 21 a 40 años (Ahmed et al., 2020). En una línea parecida, Lee (2020) utiliza el nuevo instrumento Coronavirus anxiety scale (CAS) para evaluar la ansiedad disfuncional asociada con la crisis de la COVID-19 en el contexto de EE.UU. Estos autores detectaron que mayores niveles de ansiedad, peor diagnóstico de COVID-19, aumento de consumo de alcohol y otras drogas, generan incapacidad extrema para determinadas actividades e ideación suicida. Por otra parte, Reynolds \& Wilkinson (2020) advierten desde el contexto australiano del peligro de considerar las tiendas donde se vende alcohol como de primera necesidad, es decir, que se mantienen abiertas en la pandemia. Según ellos, esto conlleva a un posible aumento de alcohol en los hogares que traería complicaciones tanto de convivencia como de favorecimiento de conductas adictivas. En otra línea totalmente distinta, un trabajo llevado a cabo desde el contexto iraní alerta sobre los graves daños que está causando en la población la desinformación referente al consumo de alcohol, debido a la expansión de información no basada en ningún tipo de evidencia científica que afirma que la ingesta de alcohol detiene la expansión del virus SARS-CoV2. Esta creencia se debe, según indican los autores, a factores culturales vinculados con la prohibición del alcohol lo que conlleva una falta de formación e información al respecto (Shalbafan \& Khademoreza, 2020).

\section{Tabaco}

En cuanto a la relación del tabaco con la COVID-19, es con diferencia la conducta adictiva que más literatura ha generado hasta el momento (un 31,6\% de los documentos analizados son sobre tabaco/nicotina). Por un lado, algunos autores señalan que existen indicios que relacionan el tabaquismo con un peor pronóstico de la enfermedad COVID-19 (Brake et al., 2020; Hefler \& Gartner, 2020). Dado que en la infección por SARS-CoV-2, el virus penetra en la célula utilizando como receptor a la enzima convertidora de angiotensina (ACE2), estas primeras evidencias científicas indican que la práctica de fumar parece participar de manera directa en un mecanismo relacionado con la habilidad de los receptores nicotínicos de regular la expresión de la proteína ACE2 en las células del pulmón (Brake et al., 2020; Hefler \& Gartner, 2020). Además, se destaca que un cigarrillo contiene, aparte de nicotina, una variedad de más de 5.000 químicos con potencial cancerígeno y de alteración de las funciones cardiovasculares y respiratorias, que también podrían contribuir al desarrollo de la enfermedad COVID-19 (Olds \& Kabbani, 2020). Por 
otra parte, Hefler \& Gartner (2020), además de indicar que la evidencia nos está señalando que las personas fumadoras hospitalizadas por COVID-19 tienen el riesgo de sufrir un peor pronóstico, critican el hecho de que en muchos países (entre ellos España o Italia) permitan que los establecimientos que venden tabaco continúen abiertos. A este respecto, argumentan que debería aprovecharse esta oportunidad para hacer frente de manera más contundente a las consecuencias sanitarias derivadas del consumo de tabaco. Actualmente, las enfermedades causadas por el consumo de tabaco son las responsables de 1 millón de muertes al año en China, casi 100.000 en Italia, y más de 55.000 en España (The Tobacco Atlas, 2020). En España, los pacientes con una enfermedad obstructiva crónica (EPOC) o con tabaquismo tienen un mayor riesgo de infección grave por COVID-19 y ello estaría provocando una mayor tasa de mortalidad en hombres debido a su relación con las enfermedades cardiovasculares (Vázquez \& Redolar, 2020). Además, otros autores también destacan que la práctica de vapear (fumar con cigarrillos electrónicos) tampoco estaría exenta de estas consecuencias nocivas, y que afectarían de un modo similar al tabaco tradicional, aunque destacan la necesidad de evidencia que lo demuestre (Gurmeet, Mds, Surgery \& Glasgow, 2020). Sin embargo, otros documentos están focalizados en los incipientes indicios de que la nicotina puede tener efectos positivos en las personas enfermas por COVID-19, señalando en algunos casos estudios que se están llevando a cabo sobre todo en China, donde, al contrario que los estudios que se han mencionado anteriormente, parecen indicar que las personas fumadoras infectadas por coronavirus ingresadas en hospitales eran porcentualmente menos frecuentes que las no fumadoras (Tindle, Newhouse \& Freiberg, 2020).

\section{Cannabis}

Con respecto al cannabis, al igual que el tabaco, su consumo se ha relacionado con consecuencias negativas en relación con la COVID-19. En el estudio multivariante y de geolocalización de Reece \& Hulse (2020), la variable de respuesta fue la "tasa de incidencia del coronavirus". Los autores ajustaron diversos modelos, en uno de ellos consideraron el efecto de: los viajes internacionales, grupo étnico, ingreso, población, densidad poblacional y consumo de drogas. Reece \& Hulse concluyeron que el consumo mensual y diario de cannabis está asociado con la "tasa de incidencia del coronavirus". En paralelo, otros estudios evalúan los efectos positivos que podría tener el componente cannabidiol (CBD) para el tratamiento de las personas enfermas de COVID-19, debido a su carácter antiinflamatorio (Sexton, 2020).

\section{Otras conductas adictivas}

Al margen de los documentos sobre las conductas adictivas descritas, también se ha encontrado el documento de Carrico et al., (2020) focalizado en los consumidores de metanfetamina que además tienen $\mathrm{VIH}$. Estos autores señalan que son un colectivo de especial riesgo por el peligro agravado para su sistema inmunológico. Hacen hincapié en que no se repitan los errores del pasado con el VIH - SIDA y se actúe con rapidez poniendo al alcance los recursos necesarios. Por otro lado, desde el contexto de los países del sur de Asia oriental, se destaca la importancia de tener en cuenta sustancias como la nuez de areca, muy consumida por esa zona, por las posibles consecuencias negativas de las personas consumidoras en el contexto de COVID19 (Kaur \& Rinkoo, 2020). Finalmente, se ha localizado un único documento donde se hace referencia exclusiva a las adicciones sin sustancia, concretamente, los videojuegos. A este respecto, se alerta sobre las consecuencias, sobre todo para la población más joven, de desarrollar conductas problemáticas por abuso de este tipo de entretenimiento, entre las que 
destacan alteraciones del sueño, falta de concentración para otras tareas o futuras dificultades a una adaptación a la vida post-confinamiento (King, Delfabbro, Billieux \& Potenza, 2020).

\section{Propuestas de actuación de los autores}

Finalmente, sobre las recomendaciones y propuestas de actuación, los autores ponen énfasis en garantizar el acceso ininterrumpido tanto al tratamiento de fármacos, como metadona, buprenorfina o naloxona en el caso de los opioides, como al mantenimiento de tratamiento psicosocial y recursos de reducción de daños, así como instan a ser innovadores con las atención haciendo uso de herramientas TIC (Alexander, Stoller, Haffajee \& Saloner, 2020; Becker \& Fiellin, 2019; Lima et al., 2020; Tsai \&Wilson, 2020). En el caso de las poblaciones aisladas, vulnerables o con menos probabilidades de consulta a este tipo de fuentes, destacan también el acceso a información contrastada y veraz sobre la pandemia y sobre los factores de riesgo y protección relacionados con las adicciones, advirtiendo de las consecuencias negativas si este trabajo de formación e información no se lleva a cabo (Jenkins et al., 2020; Shalbafan \& Khademoreza, 2020). Destacan también la necesidad de formación de estudiantes de medicina y otras disciplinas de la salud, así como de los propios profesionales sociosanitarios para ser capaces de detectar y actuar frente a conductas adictivas y su relación con la COVID-19 (da Silva, Martelli, Ferreti, Kowalskie \& da Cruz, 2020). Otra propuesta detectada es el fortalecimiento de las medidas de salud pública, que ayuden a identificar poblaciones de riesgo de salud mental y contribuir en la creación o la mejora de servicios en lugares de intervención crítica (Ahmed et al., 2020; Arya \& Gupta, 2020). En el caso de las drogas legales, sobre todo el alcohol y el tabaco, se sugiere también la limitación de su venta para intentar reducir su consumo (Hefler \& Gartner, 2020; Reynolds \& Wilkinson, 2020). Todos los autores antes mencionados recalcan, de un modo otro, que el apoyo a la salud mental en estos momentos es imprescindible y debe ser tratado como una prioridad, sobre todo entre los colectivos más vulnerables, como las personas sin hogar que además consumen algún tipo de sustancias, mencionadas específicamente como sujetos de especial protección por los autores Rolim-Lima et Al., (Rolim-Lima et al., 2020).

Tabla 1. Síntesis de los trabajos evaluados relativos a COVID-19 y sus consecuencias directas en la salud mental y las adicciones.

Además de la literatura científica, diversas instituciones a nivel internacional están movilizándose para ofrecer información sobre los efectos de la COVID-19 y las adicciones. Tanto la Oficina de Naciones Unidas contra la Droga y el Delito (UNODC) como, en el ámbito europeo, el European Monitoring Centre for Drugs and Drug Addiction (EMCDDA) y en el contexto latinoamericano por la Comisión Interamericana para el Control del Abuso de Drogas (CICAD) OEA, han advertido de las consecuencias para las personas consumidoras de sustancias como heroína y crack fumado, u otras sustancias por vía intravenosa. Las consecuencias que destacan se relacionan con agravar estados previos que ya eran problemáticos, por ejemplo, enfermedades pulmonares obstructivas crónicas, asma o enfermedades cardiovasculares, considerados factores de riesgo potenciales de la enfermedad COVID-19; como también el peligro de contagio del virus al compartir el material para el consumo. Ante esto, estas organizaciones también recomiendan encarecidamente la continuación de las terapias farmacológicas y psicosociales, así como la promoción de las medidas de higiene, el desarrollo de nuevas estrategias de comunicación por parte de los profesionales, el acceso a los recursos en la medida de lo posible, protocolos de actuación mientras dure la pandemia y el estado de alarma, y el mantenimiento de todos los servicios y formación de los profesionales (Comisión Interamericana para el Control del Abuso de 
Drogas [CICAD], 2020; European Monitoring Centre for Drugs and Drug Addiction [EMCDDA], 2020; United Nations Office on Drugs and Crime [UNODC], 2020).

\section{Conclusiones}

La principal conclusión es la marcada incidencia e interrelación de las medidas para afrontar la COVID-19 y sus consecuencias directas en la salud mental y las adicciones. La mayoría de los estudios se están centrando en consumidores de opiáceos, tabaquismo y alcohol. En relación con los primeros se constatan afecciones psiquiátricas comórbidas, que podrían aumentar las sobredosis, muy especialmente, entre aquellas personas que sufren situaciones de marginalidad y estigma. El consumo problemático de alcohol, se relacionaría con el estrés, pudiendo erigirse por tanto en un potencial detonante tanto para el inicio como para el mantenimiento de los consumos -especialmente en concurrencia con aislamiento-. Con respecto al tabaquismo y el cannabis, la tendencia no es tanto a señalar factores relacionados con el aislamiento, sino como práctica altamente perjudicial para el sistema respiratorio y debilitamiento del sistema inmunitario. Todo ello se empieza a relacionar, incipientemente, con un peor pronóstico de la enfermedad y progresión negativa, aunque también hay que tener en cuenta los estudios que hablan sobre un posible efecto positivo de la nicotina (que no del tabaco y los compuestos que forman los cigarrillos). Cabe señalar que la investigación publicada sobre cannabis en relación a la COVID-19 durante el periodo analizado es muy escasa si se compara con el tabaco, alcohol y opiáceos. Llama la atención ya que el cannabis es la droga ilegal más consumida. Es importante estar al tanto de nuevas evidencias a este respecto, ya que serán determinantes para el afrontamiento de la enfermedad.

A partir de estos antecedentes, se incide en garantizar el acceso ininterrumpido al tratamiento sustitutorio de fármacos, como metadona, buprenorfina o naloxona en el caso de los opioides, así como el mantenimiento de tratamiento psicosocial y recursos de reducción de daños muy especialmente en poblaciones vulnerables y/o aisladas.

Sin embargo, aunque todavía sabemos poco a nivel de evidencia científica, podemos intuir que las consecuencias de la pandemia para la salud mental y para las personas que sufren alguna adicción van a ser notables. Ello exigirá a los profesionales e investigadores del ámbito social y de la salud pública que redefinan y adapten sus prácticas, y la investigación a las nuevas circunstancias.

Igualmente convendría no olvidar que sustancias de curso legal como los hipnosedantes o las benzodiacepinas deberán ser igualmente muy tenidas en cuenta, al igual que las adicciones sin sustancia y que parecen estar siendo obviadas (juego patológico online, gambling, gaming, uso abusivo de nuevas tecnologías). En un contexto global de confinamiento y con las difíciles circunstancias de postconfinamiento todavía inciertas, ambiguas y con plazos flexibles según los países ello puede ser un caldo de cultivo tan peligroso tanto para las adicciones con sustancia (como hemos observado), como sin sustancia. Personas que ya padecían algún tipo de adicción verán agravada su situación de salud biopsicosocial, así como es posible que descubramos que algunas comorbilidades se agudicen, aunque todavía no sabemos de qué manera se manifestarán. Todo esto en un contexto que probablemente cambiará y redefinirá la forma en la que entendemos la salud pública. También es posible que esta situación propicie cambios positivos en las personas que padecen alguna enfermedad mental, que medidas de confinamiento ayuden a, por ejemplo, mantenerse alejado de la sustancia (muy especialmente las ilegales) e incite a un esfuerzo por dejar el consumo. Por otra parte, es posible que la situación 
favorezca la tan ansiada puesta en valor de la salud mental (reivindicada desde hace años por algunos sectores profesionales y los propios pacientes), así como del conjunto de profesionales que trabajan en el campo del tratamiento, prevención, reducción de daños e investigación de las adicciones.

\section{Conflicto de intereses}

Los autores declaran que no tienen conflictos de intereses que declarar.

\section{Agradecimientos}

Los autores agradecen la financiación otorgada por el Servicio de Drogodependencias (PMD/UPCCA-València). Concejalía de Sanidad y Consumo. Ajuntament de València, el Ministerio de Economía y Competitividad (BES-2016-079394) y el CIBERONC (CB16/12/00350).

\section{Referencias}

Ahmed, M. Z., Ahmed, O., Aibao, Z., Hanbin, S., Siyu, L., \& Ahmad, A. (2020). Epidemic of COVID19 in China and associated Psychological Problems. Asian Journal of Psychiatry, 51, 102092. doi: 10.1016/j.ajp.2020.102092

Alexander, G. C., Stoller, K. B., Haffajee, R. L., \& Saloner, B. (2020). An Epidemic in the Midst of a Pandemic: Opioid Use Disorder and COVID-19. Annals of Internal Medicine, 19-21. doi: 10.7326/M20-1141

Arya, S., \& Gupta, R. (2020). COVID-19 outbreak: Challenges for Addiction services in India. Asian Journal of Psychiatry, 51(March), 102086. doi: 10.1016/i.ajp.2020.102086

Bansal, P., Bingemann, T. A., Greenhawt, M., Mosnaim, G., Nanda, A., Oppenheimer, J., Shaker, M. (2020). Clinician Wellness During the COVID-19 Pandemic: Extraordinary Times and Unusual Challenges for the Allergist/Immunologist. The Journal of Allergy and Clinical Immunology: In Practice, 8(6), 1781-1790.e3. doi: 10.1016/j.jaip.2020.04.001

Becker, W., \& Fiellin, D. (2020). When Epidemics Collide: Coronavirus Disease 2019 (COVID-19) and the Opioid Crisis William. Annals of Internal Medicine, 1-3. https://doi.org/10.17226/25310

Brake, S. J., Barnsley, K., Lu, W., McAlinden, K. D., Eapen, M. S., \& Sohal, S. S. (2020). Smoking Upregulates Angiotensin-Converting Enzyme-2 Receptor: A Potential Adhesion Site for Novel Coronavirus SARS-CoV-2 (Covid-19). Journal of Clinical Medicine, 9(3), 841. doi: $\underline{10.3390 / \mathrm{jcm} 9030841}$

Comisión Interamericana para el Control del Abuso de Drogas. (2020). Covid-19 y el tratamiento de trastornos por uso de sustancias. Recuperado de http://sisco.copolad.eu/web/uploads/documentos/COVID19 Recomendaciones Reduccion de la Demanda Abril 30 ESP.pdf

Cai, G., Bossé, Y., Xiao, F., \& Kheradmand, F. (2020). Tobacco Smoking Increases the Lung Gene Expression of ACE2, the Receptor of SARS-CoV-2. American Journal of Respiratory and Critical Care Medicine, 201(12), 1-11. doi: 10.1164/rccm.202003-0693LE 
Carrico, A. W., Horvath, K. J., Grov, C., Moskowitz, J. T., Pahwa, S., Pallikkuth, S., \& Hirshfield, S. (2020). Double Jeopardy: Methamphetamine Use and HIV as Risk Factors for COVID-19. AIDS and Behavior, (0123456789), 1-4. doi: 10.1007/s10461-020-02854-w

Clay, J. M., \& Parker, M. O. (2020). Alcohol use and misuse during the COVID-19 pandemic: a potential public health crisis? The Lancet Public Health, 5(5), 30088-8. doi: 10.1016/S2468$\underline{2667(20) 30088-8}$

da Silva, A. C. L., Martelli, H., Ferreti, P. R., Kowalskie, L. P., \& da Cruz, D. E. (2020). COVID-19, head and neck cancer, and the need of training of health students and practitioners regarding to tobacco control and patient counseling. Oral Oncology, 106. doi: 10.1016/i.oraloncology.2020.104739

Dunlop, A., Lokuge, B., Masters, D., Sequeira, M., Saul, P., Dunlop, G., Maher, L. (2020). Challenges in maintaining treatment services for people who use drugs during the COVID-19 pandemic. Harm Reduction Journal, 17(26). doi: 10.1186/s12954-020-00370-7

Editorial. (2020). The COVID-19 pandemic and mental health impacts. International Journal of Mental Health Nursing, 29, 315-318. doi: 10.1111/inm.12726

European Monitoring Centre for Drugs and Drug Addiction. (2020). EMCDDA update on the implications of COVID-19 for people who use drugs (PWUD) and drug service providers. Retrieved from https://www.emcdda.europa.eu/publications/topicoverviews/catalogue/covid-19-and-people-who-use-drugs

García, L., de la Fuente, L., Sáiz, P. A., García, M. P., \& Bobes, J. (2020). ¿Se observarán cambios en el consumo de alcohol y tabaco durante el confinamiento por COVID-19? Adicciones, 32(2), 85-89. doi: 10.20882/adicciones.1546

Gurmeet, A., Mds, S., Surgery, M., \& Glasgow, M. (2020). Tobacco use and vaping in the COVID19 era. Head \& Neck, 42(6), 1-3. doi: 10.1002/hed.26208

Hefler, M., \& Gartner, C. E. (2020). The tobacco industry in the time of COVID-19: time to shut it down? Tobacco Control, 29(3), 245-246. doi: 10.1136/tobaccocontrol-2020-055807

Jenkins, W. D., Bolinski, R., Bresett, J., Ham, B. V., Fletcher, S., Walters, S., Ouellet, L. (2020). COVID-19 During the Opioid Epidemic - Exacerbation of Stigma and Vulnerabilities. The Journal of Rural Health, (March), 1-3. doi: 10.1111/jrh.12442

Kar, S. K., Arafat, S. M. Y., Sharma, P., Dixit, A., Marthoenis, M., \& Kabir, R. (2020). COVID-19 pandemic and addiction: Current problems and future concerns. Asian Journal of Psychiatry, 51. doi: 10.1016/j.ajp.2020.102064

Kaur, J., \& Rinkoo, A. V. (2020). Public health perspectives of smokeless tobacco and areca nut use in the COVID-19 era. Nicotine \& Tobacco Research, $x x(x x)$ 1-2. doi: 10.1093/ntr/ntaa081

King, D. L., Delfabbro, P. H., Billieux, J., \& Potenza, M. N. (2020). Problematic online gaming and the COVID-19 pandemic. Journal of Behavioral Addictions, 9(2), 184-186. doi: $\underline{10.1556 / 2006.2020 .00016}$ 
Lazcano, E., \& Alpuche, C. (2020). Alfabetización en salud pública ante la emergencia de la pandemia por Covid-19. Salud Pública de México, 62(3), 331-340. doi: 10.21149/11408

Lee, S. A. (2020). Coronavirus anxiety scale: A brief mental health screener for COVID-19 related anxiety. Death Studies, 44(7), 393-401. doi: 10.1080/07481187.2020.1748481

Lippi, G., Henry, B. M., Bovo, C., \& Sanchis, F. (2020). Health risks and potential remedies during prolonged lockdowns for coronavirus disease 2019 (COVID-19). Diagnosis, 7(2), 85-90. doi: $10.1515 / \mathrm{dx}-2020-0041$

Liu, J. J., Bao, Y., Huang, X., Shi, J., \& Lu, L. (2020). Mental health considerations for children quarantined because of COVID-19. The Lancet Child \& Adolescent Health, 4(5), 347-349. doi: 10.1016/s2352-4642(20)30096-1

Marsden, J., Darke, S., Hall, W., Hickman, M., Holmes, J., Humphreys, K., West, R. (2020). Mitigating and learning from the impact of COVID-19 infection on addictive disorders. Addiction, 115(6), 1007-1010. doi: 10.1111/add.15080

Olds, J. L., \& Kabbani, N. (2020). Is nicotine exposure linked to cardiopulmonary vulnerability to COVID-19 in the general population? The FEBS Journal, 1-5. doi: 10.1111/febs.15303

Reece, A. S., \& Hulse, G. (2020). America Addresses Two Epidemics - Cannabis and Coronavirus and their Interactions: An Ecological Geospatial Study. Journal: BMJ Open, 1-58. doi: 10.1101/2020.04.17.20069021

Reynolds, J., \& Wilkinson, C. (2020). Accessibility of 'essential' alcohol in the time of COVID-19: Casting light on the blind spots of licensing? Drug and Alcohol Review, 39(4), 7-10. doi: 10.1111/dar.13076

Rolim-Lima, N. N. R., de Souza, R. I., Gomes, P. W., de Sousa, J. L., Lima da Silva, C. G., \& Neto, M. L. R. (2020). People experiencing homelessness: Their potential exposure to COVID-19. Psychiatry Research, 288, 1-2. doi: 10.1016/j.psychres.2020.112945

Russo, P., Bonassi, S., Giacconi, R., Malavolta, M., Tomino, C., \& Maggi, F. (2020). Early View COVID-19 and Smoking. Is Nicotine the Hidden Link? European Respiratory Journal. doi: $\underline{10.1183 / 13993003.01116-2020}$

Sani, G., Janiri, D., Di Nicola, M., Janiri, L., Ferretti, S., \& Chieffo, D. (2020). Mental health during and after the COVID-19 emergency in Italy. Psychiatry and Clinical Neurosciences, 74(6), 372-373. doi: $10.1111 / \mathrm{pcn} .13004$

Satre, D. D., Hirschtritt, M. E., Silverberg, M. J., \& Sterling, S. A. (2020). Addressing problems with alcohol and other substances among older adults during the COVID-19 pandemic. The American Journal of Geriatric Psychiatry, (28)7, 780-783. doi: 10.1016/j.jagp.2020.04.012

Sexton, M. (2020). Cannabis in the Time of Coronavirus Disease 2019: The Yin and Yang of the Endocannabinoid System in Immunocompetence. The Journal of Alternative and Complementary Medicine, 26(6), 444-448. doi: 10.1089/acm.2020.0144 
Shalbafan, M., \& Khademoreza, N. (2020). What we can learn from COVID-19 outbreak in Iran about the importance of alcohol use education. The American Journal of Drug and Alcohol Abuse, 46(3), 1-2. doi: 10.1080/00952990.2020.1753759

The Tobacco Atlas. (2020). Countries. Atlanta: American Cáncer Society and Vital Strategies. Recuperado de https://tobaccoatlas.org/countries/

Tindle, H. A., Newhouse, P. A., \& Freiberg, M. S. (2020). Beyond Smoking Cessation: Investigating Medicinal Nicotine to Prevent and Treat COVID-19. Nicotine \& Tobacco Research : Official Journal of the Society for Research on Nicotine and Tobacco, xx(xx), 1-2. doi: $10.1093 /$ ntr/ntaa077

Tsai, J., \& Wilson, M. (2020). COVID-19: a potential public health problem for homeless populations. The Lancet Public Health, 5(4), e186-e187. doi: 10.1016/S24682667(20)30053-0

United Nations Office on Drugs and Crime. (2020). Suggestions about treatment, care and rehabilitation of people with drug use disorder in the context of the COVID-19 pandemic. Panama: UNODC. Recuperado de https://www.unodc.org/ropan/en/suggestions-abouttreatment--care-and-rehabilitation-of-people-with-drug-use-disorder-in-the-context-ofthe-covid-19-pandemic.html

Usher, K., Bhullar, N., \& Jackson, D. (2020). Life in the pandemic: Social isolation and mental health. Journal of Clinical Nursing, 29(15-16), 2756-2757. doi: 10.1111/jocn.15290

Vázquez, J., \& Redolar-Ripoll, D. (2020). COVID-19 outbreak impact in Spain: A role for tobacco smoking? Tobacco Induced Diseases, 18, 1-2. doi: 10.18332/tid/120005

Vecchio, S., Ramella, R., Drago, A., Carraro, D., Littlewood, R., \& Somaini, L. (2020). COVID19 pandemic and people with opioid use disorder: innovation to reduce risk. Psychiatry Research, 289, 113047, 1-2. doi: 10.1016/i.psychres.2020.113047

Volkow, N. D. (2020). Collision of the COVID-19 and Addiction Epidemics. Annals of Internal Medicine, 173(1), 61-62. doi: $10.7326 / \mathrm{m} 20-1212$

Wakeman, S. E., Green, T. C., \& Rich, J. (n.d.). An overdose surge will compound the COVID-19 pandemic if urgent action is not taken. Nature Medicine, 26, 819-820. doi: 10.1038/s41591-020-0898-0

Wilson, C. G., Ramage, M., \& Fagan, E. B. (2020). A Primary Care Response to COVID-19 for Patients with an Opioid Use Disorder. The Journal of Rural Health, 1-3. doi: 10.1111/jrh.12438

Yang, Y., Li, W., Zhang, Q., Zhang, L., Cheung, T., \& Xiang, Y. T. (2020). Mental health services for older adults in China during the COVID-19 outbreak. The Lancet Psychiatry, 7(4), e19. doi: 10.1016/S2215-0366(20)30079-1. 